\title{
Breast cancer: 2 case reports
}

\author{
Cancer de mama: 2 casos clínicos
}

\author{
Aristóteles Rosmaninho ${ }^{1}$ \\ Mónica Caetano ${ }^{3}$
}

\author{
Glória Velho ${ }^{2}$ \\ Manuela Selores $^{4}$
}

\begin{abstract}
Breast cancer is the most frequently diagnosed life-threatening cancer in women and the leading cause of cancer death among them worldwide. It includes a heterogeneous collection of diseases with various histologically defined subsets, clinical presentations, responses to treatment and outcomes. We describe 2 cases of female patients with ductal breast carcinoma. Dermatologists may have an important role in diagnosing such diseases.

Keywords: Breast neoplasms; Carcinoma, ductal, breast; Cancer; Medical oncology; Neoplasms

Resumo: Mundialmente, o câncer de mama é o câncer com risco de vida mais frequentemente diagnosticado em mulheres, sendo a principal causa de morte por câncer entre estas. Inclui um grupo heterogêneo de doenças com vários subgrupos histologicamente definidos, várias apresentações clínicas, respostas e resultados ao tratamento. Nós descrevemos dois casos de pacientes do sexo feminino com carcinoma ductal da mama. O dermatologista pode ter um papel importante no diagnóstico destas doenças.

Palavras-chave: Cancro; Carcinoma ductal de mama; Neoplasias; Neoplasias da mama; Oncologia
\end{abstract}

\section{INTRODUCTION}

Invasive breast cancer is a heterogeneous disease regarding its clinical presentation, pathological classification and clinical course. Most tumors are derived from mammary ductal epithelium, mainly the terminal duct-lobular unit and up to $75 \%$ of the diagnosed infiltrating ductal carcinoma are defined as invasive ductal carcinoma. Invasive lobular carcinoma, which comprises up to $15 \%$, is the second most common epithelial type. ${ }^{1}$ Many risk factors for the development of breast cancer have been identified through epidemiological studies. Gene profiling led to the discovery of different molecular subtypes with phenotypic diversity concerning clinical outcome, including response to treatment, disease-free survival and overall survival. ${ }^{2}$ Nowadays, local advanced disea- se is not frequently seen as in the past because of the availability of information and the widespread use of screening mammography. However, advanced local disease may be found as in the present reports.

\section{CASE REPORT}

\section{Case Report 1}

A 31-year-old woman presented for dermatological evaluation because of a seven-month history of skin changes in her left breast. She had given birth 8 months before and noticed an induration and asymmetry of her breasts one month after delivery. She complained to her gynecologist but the alterations were misinterpreted due to breastfeeding. She had no personal or family history of breast or ovarian cancer.

Received on 22.03.2011.

Approved by the Advisory Board and accepted for publication on 14.05.2011.

* Study carried out at the Dermatology Service, Porto Hospital Center (Centro Hospitalar do Porto - Hospital Santo António - EPE - HSA) - Porto, Portugal Conflict of interest: None / Conflito de interesse: Nenhum Financial funding: None / Suporte financeiro: Nenbum

Physician. Internist in Dermatovenereology at Porto Hospital Center (Centro Hospitalar do Porto - Hospital Santo António - EPE - HSA) - Porto, Portugal. Physician. Hospital Assistant with a degree in Dermatovenereology, Porto Hospital Center (Centro Hospitalar do Porto - Hospital Santo António - EPE - HSA) - Porto, Portugal

Physician. Hospital Assistant in Dermatovenereology, Porto Hospital Center (Centro Hospitalar do Porto - Hospital Santo António - EPE - HSA) - Porto, Portugal.

Physician. Director of the Dermatovenereology Service, Porto Hospital Center (Centro Hospitalar do Porto - Hospital Santo António - EPE - HSA) - Porto, Portugal. 

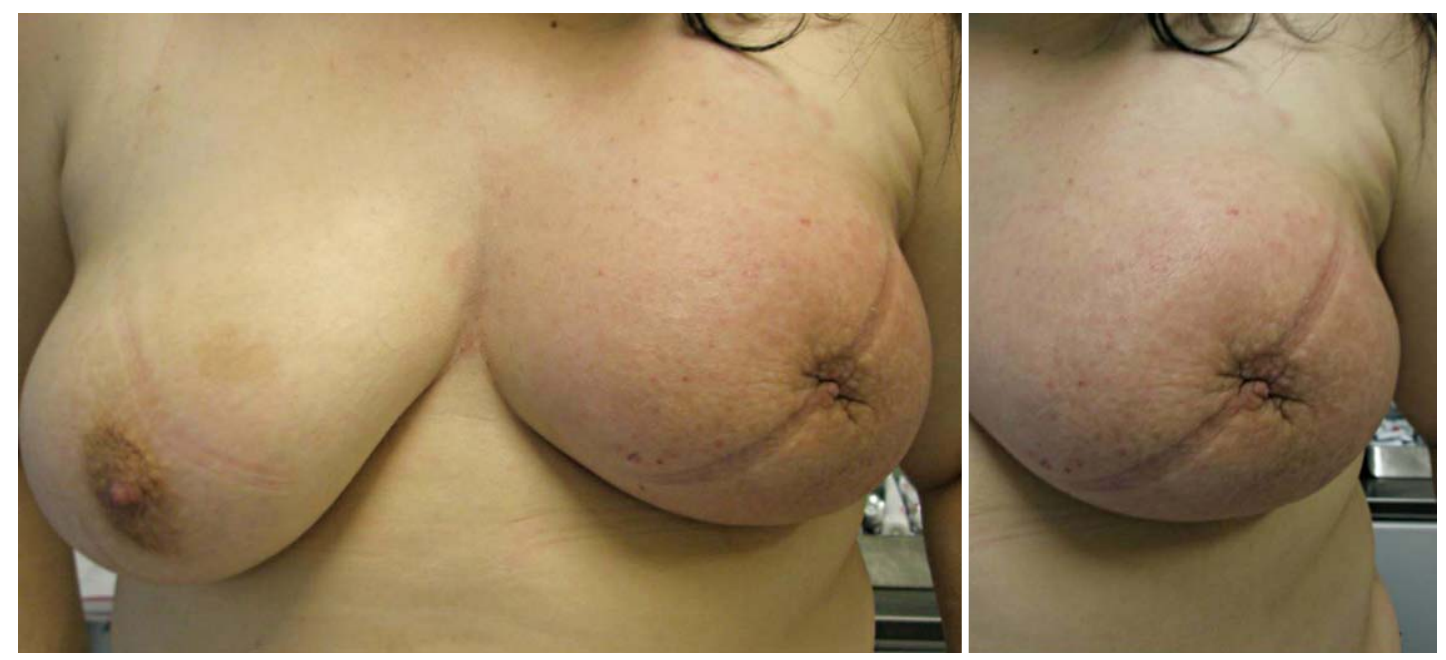

Figure 1: Clinical aspects of the disease in case report 1

On physical examination her left breast was smaller and edema, erythema, induration and peau d'orange were observed (Figure 1). Left axillary adenopathies were palpable. Because breast cancer was suspected a deep skin biopsy was performed. Hematoxylin-eosin stain showed a high grade ductal carcinoma with dermal invasion. Molecular analysis showed that the tumor was ER-negative (estrogen receptors), PR-negative (progesterone receptors) and HER-2 (human epidermal growth factor receptor-type 2)-positive $(3+)$ (Figure 2).

\section{Case Report 2}

A 77 year-old-woman was followed in our outpatient-clinic because of actinic keratosis. At her third visit she complained about the size and nipple inversion of her left breast that she had neglected for one

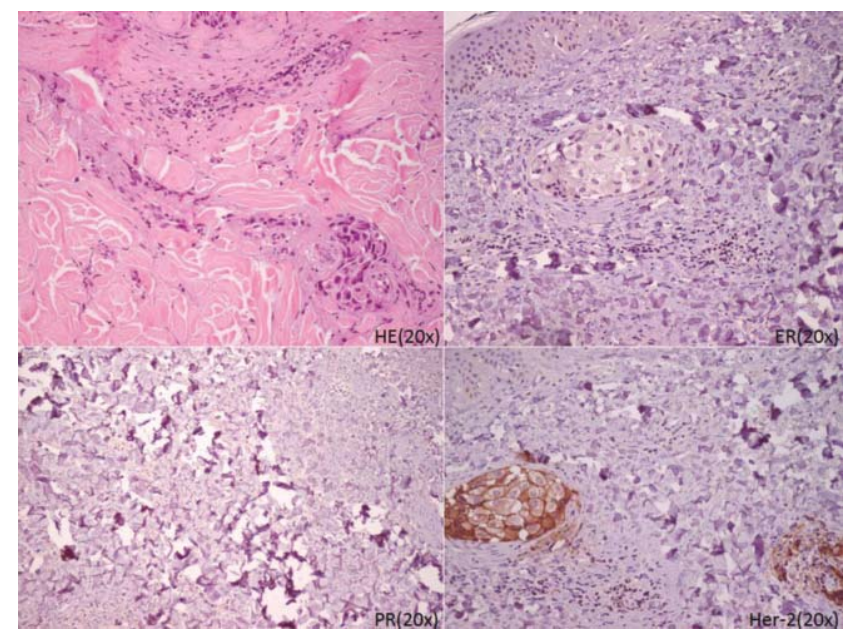

Figure 2: Histological features of the tumor. Hematoxylin-eosin showed a ductal carcinoma. The tumor was ER-negative, PR-negative and HER-2-positive $(3+)$ year. She had no personal or family history of breast or ovarian cancer. On physical examination inversion of the nipple with a contiguous erythematous, round plaque and an irregular mass on her left breast were observed (Figure 3). There were no palpable adenopathies. A skin biopsy was performed because of breast cancer suspicion. Hematoxylin-eosin stain revealed a poor differentiated ductal carcinoma with skin invasion. Molecular analysis showed that the tumor was ER-positive for $30 \%$ of tumor cells, PRnegative and HER-2-positive (2+) (Figure 4).

\section{DISCUSSION}

Early detection of breast cancer remains the best defense for preventing development of this lifethreatening disease. Tumors that are smaller and nonpalpable are more treatable and have a better prognosis. In our reports a considerable delay in diagnosis was observed, resulting in advanced disease and poor outcomes. Epidemiological data have identified several risk factors for the development of breast cancer. The common denominator for those risk factors is the level and duration of exposure to endogenous estrogen. Thus an early age of menarche, a late age of menopause and the use of hormone replacement therapy increased the risk of having breast cancer. ${ }^{3}$ Other factors include older age at diagnosis, a family history of breast or ovarian cancer, lifestyle factors such as adult weight gain, a sedentary life style or alcohol consumption. Several histological factors have prognostic value including: histology and size of the primary tumor, nuclear pleomorphism and mitotic index. ${ }^{4}$

Early breast cancer has no symptoms. Most of the time the disease is discovered before symptoms are present, either by abnormal findings in mammography or feeling a breast lump. Any of the following unusual breast changes can be a first sign of breast 


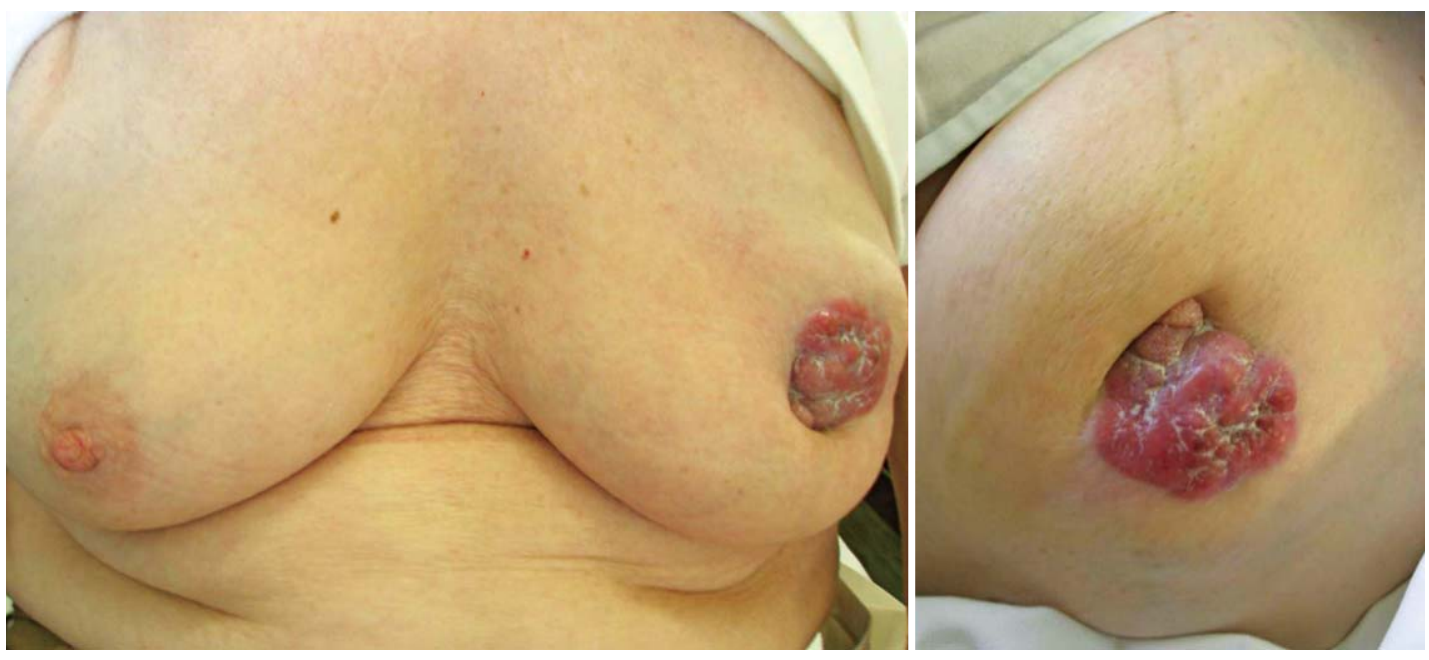

Figure 3: Clinical aspects of the disease in the case report 2 cancer, including invasive ductal carcinoma: swelling of all or part of the breast, skin irritation or dimpling, breast pain, nipple pain or the nipple turning inward, redness, scaliness, or thickening of the nipple or breast skin, a nipple discharge other than breast milk or a lump in the underarm area.

Although most breast cancers begin as lumps or tumors, inflammatory breast cancer usually starts with a feeling of thickness or heaviness in the breast. Most of the patients complain about a change in color of one of the breasts; usually a pink color evolves into a darker red and rapidly spreads over the entire breast. Edema involving more than two-thirds of the breast is a hallmark of inflammatory breast cancer. Sometimes the redness comes and goes. A sensation of heat and rapid enlargement of the affected breast over a period of only a few weeks are usual complaints. Fever is not usually present and up to $30 \%$ of patients will present with no underlying palpable masses. ${ }^{5}$ Due to the aggressive character of the tumor axillary adenopathies may be found. This type of breast cancer is clinically defined by rapid onset of symptoms including breast edema, warmth, erythema and induration. ${ }^{6}$ It has a worse clinical outcome compared to stage-matched noninflammatory cancers. The differential diagnosis includes other benign and malignant diseases. In the first report lactation mastitis was ruled out. Localized tenderness, fever, and leukocytosis are characteristic features of lactation mastitis, which is present in up to $10 \%$ of lactating women. ${ }^{7}$ Symptoms evolve within a few days and improvement occurs within 24 to 48 hours after initiating antibiotherapy. Breast skin cellulitis also responds to treatment with antibiotics. Phlebitis of the thoracoepigastric vein should also be considered in the differential diagnosis. Usually it is preceded by trauma and manifests as a painful, palpable cord. ${ }^{7}$ It is advisable to perform a mammogram in women older than 35 years of age because it can be associated with malignancy. Leukemic infiltration of the breast can also occur with similar features of inflammatory breast cancer; however, these patients are usually systemically unwell, and a peripheral blood smear is usually enough to distinguish between both diseases. In case report 2, the differential diagnoses included: duct ectasia and fat necrosis. Duct ectasia is a benign entity that occurs when ducts beneath the nipples become clogged with fatty material, producing a lump. It occurs in perimenopausal and postmenopausal women. Itching or a burning sensation around the nipple with a thick discharge are frequent complaints, although less than one-third of the breast is involved. Subareolar abscesses are possible complications. Fat necrosis is a rare breast lesion but it is of clinical importance because it

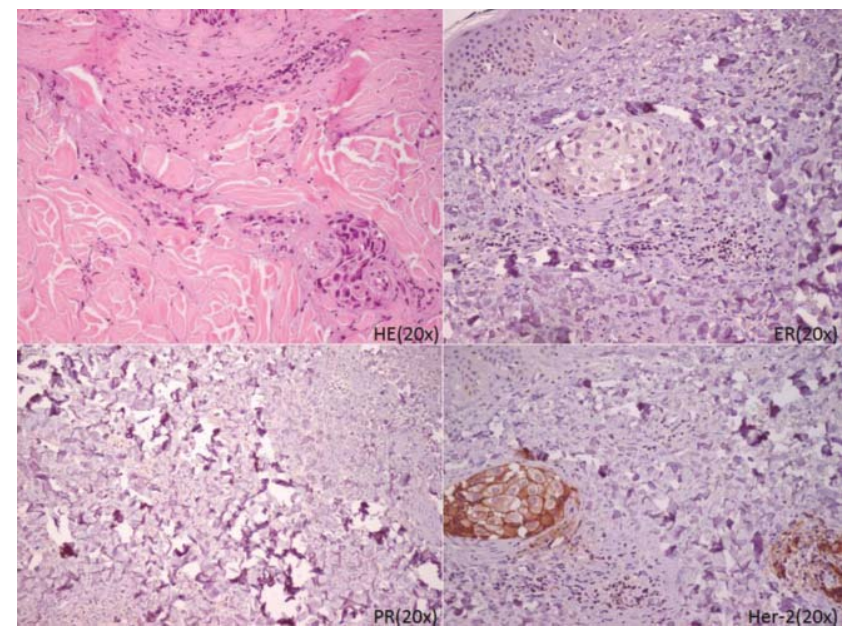

Figure 4: Histological features of the tumor. Hematoxylin-eosin showed an invasive ductal carcinoma. The tumor was ER-positive for $30 \%$ of tumor cells, PR-negative and HER-2-positive $(2+)$ 
produces a mass, often accompanied by skin or nipple retraction, which is indistinguishable from carcinoma. Although trauma is presumed to be the cause, only about $50 \%$ of patients give a history of injury. Ecchymosis may be seen. The safest course is to obtain a biopsy and most of the times the entire mass needs to be excised to exclude carcinoma. Regarding interactions between pregnancy and breast cancer it seems that women of childbearing age experience an increased breast cancer risk associated with a completed pregnancy. However, within a decade after parturition a crossover effect results in an ultimate protective benefit. ${ }^{8}$ Maternal age greater than 30 at first birth results in an elevation of the peak incidence of the disease in the first postpartum years. In contrast, lactation seems to reduce the risk for breast cancer in $4.3 \%$ to $64 \%$. ${ }^{9}$ In general, hormone-positive tumors have a more indolent course. Tumors that express estrogen receptors (ER) are more likely to respond to antiestrogens and those that are ER-negative are refractory to hormonal manipulation. The amplification of the HER-2/neu oncogene predicts poor clinical outcome. ${ }^{10}$ As expected due to the clinical and molecular features of the tumors, the first patient had a worst outcome than the second and died within 1 year after the diagnosis. The second patient responded well to chemotherapy and is still alive 2 years after the diagnosis. We present 2 cases that are not usually seen in dermatological evaluations, showing that dermatologists may have an important role in diagnosing breast cancer. Physicians should be able to recognized this entity and its differential diagnoses in order to contribute to the decrease of mortality and morbidity through early detection of the disease.

\section{REFERENCES}

1. Yerushalmi R, Hayes MM, Gelmon KA. Breast carcinoma-rare types: review of literature. Ann Oncol. 2009;20:1763-70.

2. Pazaiti A, Fentiman IS. Basal phenotype breast cancer: implications for treatment and prognosis. Women's Health (Lond Engl). 2011;7:181-202.

3. Collaborative Group on Hormonal Factors in Breast Cancer. Breast cancer and hormonal contraceptives:collaborative reanalysis of individual data on 53,297 women with breast cancer and 100,239 women without breast cancer from 54 epidemiological studies. Lancet. 1996;347:1713-27.

4. Elston CW, Ellis I0. Pathological prognostic factors in breast cancer I. The value of histological grade in breast cancer: Experience from a large study with long-term follow-up. Histopathology. 1991;19:403-10.

5. Singletary SE, Cristofanilli M. Defining the clinical diagnosis of inflammatory breast cancer. Semin Oncol. 2008;35:7-10.

6. Quinete S, Carvalho CR. Carcinoma inflamatorio de mama. An Bras Dermatol. 1981;56:67-70

7. Givens ML, Luszczak M. Breast disorders: a review for emergency physicians. J Emerg Med. 2002;22:59-65

8. Lord SJ, Bernstein L, Johnson KA, Malone KE, McDonald JA, Marchbanks PA, et al. Breast cancer risk and hormone receptor status in older women by parity, age of first birth, and breastfeeding: a case control study. Cancer Epidemiol Biomarkers Prev. 2008;17:1723-30.
9. Collaborative Group on Hormonal Factors in Breast Cancer. Breast cancer and breastfeeding: collaborative reanalysis of individual data from 47 epidemiological studies in 30 countries, including 50,302 women with breast cancer and 96,973 women without the disease. Lancet. 2002;360:187-95

10. Slamon DJ, Clark GM, Wong SG, Levin WJ, Ullrich A, McGuire WL. Human breast cancer: correlation of relapse and survival with amplification of the Her-2/neu oncogene. Science. 1987;235:177-82.
MAILING ADDRESS / ENDEREÇO PARA CORRESPONDÊNCIA: Aristóteles Rosmaninho

Rua D. Manuel II, $s / n^{\circ}$, Edifício das consultas externas, 4099-001, Porto, Portugal

E-mail: arisrosmaninbo@gmail.com

How to cite this article/Como citar este artigo: Rosmaninho A, Velho G, Caetano M, Selores M. Breast cancer: 2 case reports. An Bras Dermatol. 2012;87(1):123-6. 